\title{
Macrofossil evidence for pleuromeialean lycophytes from the Triassic of Antarctica
}

Benjamin Bomfleur, Michael Krings, Edith L. Taylor, and Thomas N. Taylor

Acta Palaeontologica Polonica 56 (1), 2011: 195-203 doi: http://dx.doi.org/10.4202/app.2010.0022

Triassic microfloras from Antarctica contain abundant lycophyte spores. However, macrofossils of this group of plants are missing, and thus the precise affinities of the spore producers remain unknown. Macrofossil remains of a pleuromeialean lycophyte, including an incomplete strobilus, isolated sporophylls and sporangia, as well as abundant megaspores, occur on a single rock sample from the central Transantarctic Mountains. Also occurring on the same surface is Mesenteriophyllum serratum, a strap-shaped leaf morphotype of uncertain affinity previously known only from the Kyrgyz Republic and the Taimyr Peninsula. The leaves display alternating transverse ridges and depressions that are similar to structures seen in compressed leaves of various isoetalean lycophytes. Leaf morphology and anatomy, together with the close association of the other lycophyte remains, suggest that $M$. serratum represents a pleuromeialean lycophyte leaf, which was part of the same plant that produced the sporophylls and sporangia. Sedimentological data indicate that this lycophyte inhabited a swampy, probably coal-forming overbank environment, which contrasts with the assumed xero- to halophytic habit of many other pleuromeialean lycophytes.

Key words: Isoetales, Pleuromeia, Mesenteriophyllum, phytogeography, palaeoecology, air chambers, Transantarctic Mountains.

Benjamin Bomfleur [bennibomfleur@gmx.de], Forschungsstelle für Paläobotanik am Institut für Geologie und Paläontologie, Westfälische Wilhelms-Universität Münster, Hindenburgplatz 57, D-48143 Münster, Germany; Michael Krings [m.krings@1rz.uni-muenchen.de], Department für Geo- und Umweltwissenschaften, Paläontologie und Geobiologie,

Ludwig-Maximilians-Universität, and Bayerische Staatssammlung für Paläontologie und Geologie, Richard-Wagner-Straße 10, D-80333 Munich, Germany; Edith L. Taylor[etaylor@ku.edu ] and Thomas N. Taylor [tntaylor@ku.edu], Department of Ecology and Evolutionary Biology and Natural History Museum and Biodiversity Research Center, 1200 Sunnyside Ave, Haworth Hall, University of Kansas, Lawrence, KS, 66045-7534, USA. 
This is an open-access article distributed under the terms of the Creative Commons Attribution License (for details please see creativecommons.org), which permits unrestricted use, distribution, and reproduction in any medium, provided the original author and source are credited.

Forif Full text $(952.9 \mathrm{kB})$ 